\title{
RELAÇÃO UNIVERSIDADE X EMPRESA NO BRASIL: TRANSFORMAÇÕES RECENTES E IMPLICAÇÕES PARA A AVALIAÇÃO INSTITUCIONAL ${ }^{1}$
}

\author{
Stela Maria MENEGHEL* \\ Débora Luz de MELLO** \\ Sandra de Negraes BRISOLA**
}

\section{Resumo:}

Nos últimos anos, novas demandas têm sido apresentadas para a Universidade, provocando uma revisão nos papéis que ela exerce nos sistemas de produção de Ciência e Tecnologia, de ensino, de qualificação para o trabalho, entre outros. Nesse novo ambiente, a necessidade de uma maior vinculação com o setor produtivo vem ganhando um destaque crescente na literatura especializada e nos documentos de formulação de políticas. Essas transformações recentes impactam também os mecanismos de Avaliação Institucional. Este trabalho, baseado em estudos bibliográficos e análise de entrevistas realizadas com docentes de três destacadas instituições brasileiras de ensino e de pesquisa, buscou identificar: a) elementos característicos da dinâmica interna; ou seja, as características da interação Universidade Setor produtivo, segundo a perspectiva dos atores envolvidos no processo; b) possíveis "tendências" da relação Universidade x Empresa no Brasil; c) implicações para o processo de Avaliação Institucional nas Universidades.

Palavras-chave: Universidade, Universidade x Empresa, Avaliação Institucional, interação, cooperação.

\section{Abstract:}

In the last few years, new demands were put forward for the University, changing the roles it plays in the Science and Technology, education, and qualification systems. In this new environment the need for a stronger connection with the productive sector is being increasingly highlighted in the specialized literature and in documents on policy formulation. The mechanisms of Institutional Assessment are also affect by these

* Doutora em Educação Professora da FURB. Email: stmeneg@zaz.com.br

* Doutora do Departamento de Política Científica e Tecnológica do Instituto de Geociências/Unicamp. Email: deboramello@ibm.net

*** Professora do Departamento de Política Científica e Tecnológica do Instituto de Geociências/Unicamp. Email: brisolla@turing.unicamp.br 
transformations. This paper, based on bibliographical surveys and on the analysis of interviews conducted with the faculty of three outstanding Brazilian education and research institutions, has sought to identify:

a) typical elements of their internal dynamics, that is, the features of the interaction University-Productive Sector, according to the views of the actors involved in the process;

b) possible "trends" in the relation UniversityxIndustry in Brazil; c) impacts for the process of Institutional Assessment in the Universities.

Keywords: University; University x Industry; Institutional Assessment; interaction; cooperation.

\section{I-Introdução}

Nos últimos anos, novas demandas econômicas e sociais têm sido colocadas para a Universidade, gerando discussõ es e exigindo transformações no seu modo de atuação; ou seja, uma revisão dos vários papéis que ela exerce nos sistemas de produção de Ciência e Tecnologia (C\&T), de ensino, de qualificação para o trabalho, entre outros. A vinculação com o setor produtivo é um dos aspectos mais destacados deste processo. A literatura sobre 0 tema aponta 0 crescimento de novas formas e mecanismos de interação entre Universidade e Empresas (UxE), além de alterações no comportamento dos pesquisadores. Para muitos autores, tais transformações estariam conduzindo a mudanças no modo de produção do conhecimento.

Ao mesmo tempo, acentua-se o desafio de assegurar a excelência acadêmica e melhorar as condições de desenvolvimento das atividades exercidas pelas Instituições de Ensino Superior (IES), fazendo com que a qualidade seja uma das questões centrais da discussão sobre mudanças. A avaliação Institucional tem sido utilizada como ferramenta para mensurar a qualidade acadêmica e científica, permitindo o planejamento e definição de políticas institucionais e, também, a prestação de contas à sociedade sobre o desempenho da Universidade. Ela pode contribuir para que as IES repensem, de forma crítica, práticas administrativas, acadêmicas, curriculares, de relacionamento com a sociedade, auxiliando a identificar potenciais e limites quanto à forma de atuação e, também, soluções e novas metas a serem alcançadas.

Mas, segundo CowEN (1996), a Avaliação Institucional também pode ser utilizada pelo Estado como meio de ajustar as IES ao sistema econômico com a pretensão de melhoria/controle da qualidade e, em última instância, como forma de adequá-las às necessidades do mercado. Ações neste sentido incluem, por exemplo, controle de custos, orçamento, percepção e atendimento de novas demandas. Como alerta DiAs SobRinho $(1997,58)$, a Avaliação Institucional "está no centro da discussão do que deve ser a Universidade 
relativamente a seu papel na construção da sociedade e na produção do futuro. Conseqüentemente, não é neutra, nem irrelevante, nem interessa somente à Universidade ...é inescapavelmente uma questão de interesse social e público".

Este trabalho surgiu de uma reflexão sobre as implicações que as recentes transformações observadas nas IES, decorrentes de sua aproximação com o setor produtivo, podem trazer à Avaliação Institucional. Foram analisados estudos de caso sobre Centros de Excelência que estabeleceram laços estreitos de interação com o setor produtivo, além de entrevistas com pesquisadores que têm desenvolvido projetos de cooperação com o mesmo, a fim de identificar características da dinâmica interna da interação UxE no Brasil. Em outras palavras: verificou-se o que tem caracterizado, da perspectiva do relacionamento entre os atores, a interação entre Universidade e Setor Produtivo no país e, particularmente, a seus aspectos recorrentes.

Os resultados da análise realizada mostram-se de grande importância para o processo de Avaliação Institucional, visto que permitem a esta ultrapassar o objetivo de adequação/ajuste ao mercado, fornecendo elementos para discutir implicações destas transformações para futuros cenários e projetos de Universidade.

Cabe destacar que as peculiaridades do contexto socioeconômico dos pesquisadores/instituições analisados, bem como uma revisão das políticas de promoção da relação UxE existentes no país não foram objeto deste estudo, pois tais questões já foram discutidas em outros trabalhos ${ }^{2}$.

\section{II - Metodologia}

Com o objetivo de caracterizar elementos relativos à dinâmica interna do relacionamento UxE no Brasil, buscamos dois tipos de dados: 1) bibliográficos: descrição, pela literatura local, de casos de interação UxE; 2) empínicos: percepções sobre o relacionamento feitas por pesquisadores que desenvolveram parcerias com o setor produtivo.

A bibliografia selecionada foi composta de estudos de caso sobre Centros de Excelência que estabeleceram cooperação produtiva com o setor empresarial. Foram utilizadas publicações: a) dos Cadernos de Gestão Tecnológica do Núcleo de Política e Gestão em C\&T (NPGCT/USP) - oito estudos; b) dos trabalhos realizados pelo Núcleo de Pesquisa sobre o Ensino Superior (NUPES/USP) sobre o potencial de cooperação UxE em duas Universidades paulistas - três estudos; c) do livro organizado por Vessuri, La academia va ao mercado - sete estudos ${ }^{3}$. Em Vessuri prevalece o enfoque sociológico; nas publicações do NUPES e do NPGCT o enfoque reside na gestão. Apesar de várias ponderações quanto ao contexto histórico e institucional, 
estes estudos de caso não tiveram por objetivo abordar esses aspectos, nem mesmo aqueles relativos a políticas públicas de interação UxE.

Os dados empíricos analisados foram 52 entrevistas, realizadas entre 1996 e 1997, com professores/pesquisadores das áreas de Ciências Biológicas e de Engenharia e Tecnologia. Os entrevistados foram selecionados devido ao fato de possuírem larga experiência no desenvolvimento de projetos de interação com o setor produtivo e por pertencerem a instituições cujo perfil facilita tal aproximação. São elas: a) Universidade Estadual de Campinas/Unicamp - criada nos anos 60 com motivação para interagir com o meio externo; b) Escola Politécnica da Universidade Estadual de São Paulo/EPUSP - com vasta tradição no desenvolvimento de produtos e processos na área de engenharia; c) Instituto de Pesquisas Tecnológicas/IPT - reconhecido nacionalmente por sua atuação em tecnologia industrial ${ }^{4}$.

\section{III-As Relações Universidadex Empresa}

O modelo de Universidade voltada para o ensino e a pesquisa, que se tornou dominante após a fundação da Universidade de Berlim, no início do século XIX, vem enfrentando severas críticas. Para diversos autores, as transformações observadas nos campos científico e tecnológico e nas políticas governamentais de apoio ao ensino e à pesquisa, bem como a disseminação de novas formas organizacionais de estruturação dos grupos de pesquisa, parecem conduzir a novas formas de atuação e estruturação da Universidade. Já não parece ser suficiente realizar ensino e pesquisa de mérito reconhecido para continuar a receber recursos estatais; também faz-se necessário contribuir para o desenvolvimento econômico regional ${ }^{5}$.

Nesse contexto, toma vulto nos órgãos governamentais de C\&T, no setor empresarial e nas Universidades, o tema das relações UxE. Segundo a literatura internacional e nacional (ETZKowitz \& PETERS, 1991; WeBSTER, 1994 (A E B); SutZ, 1994; PlonsKi,1990; VelHo, 1996), tais relações vêm se ampliando por uma série de razões. Para as empresas, o alto custo e risco da Pesquisa e Desenvolvimento (P\&D) necessária ao desenvolvimento de produtos e serviços intensivos em conhecimento científico conduz ao interesse no estabelecimento de acordos com outras instituições, especialmente para pesquisas précompetitivas. Para as Universidades, os esforços de interação refletem a busca de alternativas para o financiamento de atividades em decorrência da diminuição de seu orçamento. Mas também representam a busca de novas estruturas para operar num ambiente que passa por transformações decorrentes de tecnologias que aproximam, cada vez mais, a pesquisa acadêmica e a aplicação industrial. E, não menos importante, reflete a busca de legitimação do trabalho científico junto à sociedade que mantém as instituições universitárias. 
Vários estudiosos deste tema consideram que o crescimento das atividades de cooperação UxE nos últimos anos vem estabelecendo novas formas e mecanismos de interação entre ambos e acarretando mudanças no comportamento dos pesquisadores, conforme se verá a seguir.

\section{III.1- Novas formas emecanismos deinteração}

Diferentes estratégias de interação UxE têm sido citadas na literatura internacional, incluindo os acordos de cooperação; a criação de empresas spin-offs; a criação de centros ou projetos de pesquisa cooperativa; os parques tecnológicos; e, mantendo uma tradição iniciada anteriormente, os trabalhos de consultoria.

Os acordos de cooperação UxE sem envolvimento do Governo Federal, que permitiam a associação de equipes de pesquisa de Universidades com empresas dispostas a investir fortemente em novos campos do conhecimento, tornaram-se freqüentes nos países centrais nos anos 70 e 80 . Eles envolviam apenas duas entidades (Universidade e Empresa) e alcançavam valores bastante significativos ${ }^{6}$.

A criação de empresas por parte de professores universitários para buscar capital de risco (as denominadas empresas spin-offs), foi outro mecanismo bastante disseminado. Estudo sobre cinqüenta universidades norte-americanas indicou que todas elas deram origem ao menos a uma empresa, sendo que, na área de Biotecnologia, dentre 86 empresas, 47 tinham como fundador um acadêmico (ETzKowITz e PETERS, 1991). A criação de empresas é representativa em algumas universidades, especialmente em determinados setores do conhecimento, como Computação e Biologia Molecular.

Os projetos de pesquisa cooperativa e, com destaque, os programas implantados pela National Science Foundation/NSF (Programa de Centros de Pesquisa Cooperativa) disseminados em diferentes regiões, baseavam-se na premissa de que uma nova configuração das atividades de pesquisa - caracterizada pela necessidade de maior interdisciplinariedade, pela colaboração entre diferentes agentes econômicos e pela estruturação de redes e consórcios tornava necessário incentivar novas formas para sua organização e financiamento.

O modelo de parques tecnológicos, como aqueles vinculados à Stanford University (EUA) e os de Cambridge (Reino Unido), difundiram-se amplamente. Países como Estados Unidos, França, Reino Unido e Alemanha investiram fortemente nessa modalidade. Muitos dos parques implantados nos anos 80 foram localizados próximos ao câmpus de uma universidade e consistiram, também, numa alternativa para atingir maior aproximação entre universidade e empresas da região. 
A expansão destas novas formas de interação estimulou alterações na administração das Universidades. Assim, se antes as relações eram mediadas por professores, após o incentivo à aproximação, as Universidades passaram, cada vez mais, a implantar unidades especializadas em assessorar e 'vender' os resultados das pesquisas. Dentre estes mecanismos para apoio à interação os mais freqüentemente citados são os escritónios de contratos e convênios e os escritórios de relações industriais para registros de patentes e marketing. Segundo ETzKowitz e Peters (1991), até poucos anos atrás esse tipo de escritónio/elo era raro nas estruturas centrais das universidades. Em razão das mudanças descritas, porém, estudo da NSF identificou, nos EUA, 464 diferentes mecanismos de transferência de tecnologia; muitas universidades européias também possuem seu próprio escritónio de interação (DiERDONCK e outros, 1990).

Deve-se registrar que essas novas relações têm dado origem a diversos conflitos, tais como a compatibilização de tarefas do professor que continua suas atividades na universidade após criar uma empresa ou fazer parte do board de uma indústria; a participação acionária da universidade nas novas empresas ; o redirecionamento da pós-graduação para atender aos interesses do setor produtivo. Tais questões também têm conduzido à implantação de escritórios nas universidades para assessoria em aspectos jurídicos, em disputas envolvendo empresas, para o monitoramento do comportamento dos pesquisadores e outros.

\section{III2-Alteração no comportamento dos pesquisadores}

Outro aspecto explorado por diferentes autores quanto ao relacionamento UxE refere-se à alteração no comportamento dos pesquisadores. Para ZimAN (1989) há alterações decorrentes desta relação influindo na gestão das atividades acadêmicas, nos objetivos da pesquisa e no comportamento dos pesquisadores. Segundo ele, tanto as estruturas organizacionais da pesquisa acadêmica quanto as da pesquisa industrial estão sendo modificadas com 0 aumento da interação. Haveria dois grandes 'grupos' de pesquisadores, identificados segundo a forma de atuação e as normas e métodos utilizados: os universitários ou pertencentes às instituições de pesquisa, que se organizam segundo o modelo mertoniano ${ }^{8}$, e os pesquisadores dos laboratórios empresariais.

De acordo com este autor, há uma forte tendência nas administrações universitárias e nos órgãos gestores de C\&T em substituir o modelo mertoniano pelo modelo empresarial, pois os princípios do primeiro parecem consistir em impedimentos para o desenvolvimento da ciência utilitária. Entretanto, como este modelo foi fundamental para o avanço da ciência no último século, abandoná-lo pode ser indesejável para o desenvolvimento científico. 
Para ETzKowitz (1989) as alterações no comportamento dos pesquisadores são indicativas de mudanças normativas pois, em função da redução e das incertezas dos financiamentos federais, os imperativos institucionais para a obtenção de fundos têm dirigido a forma de organização da ciência. Nesse sentido, a invenção de termos como 'segredo limitado' e o uso de frases como 'extensão do conhecimento através da comercialização da pesquisa' estariam exteriorizando as transformações ocorridas na academia.

\section{III.3-AInteração Universidade-Empresa nas Economias Latino-Americanas}

A cooperação UxE na América Latina apresenta algumas características diferenciadas em relação aos países centrais. Segundo VessuRi (1994) os clientes externos das Universidades nessa região, na sua grande maioria, têm sido as grandes empresas públicas, pois representam os setores tecnologicamente mais avançados e com melhor dotação de recursos humanos. A cooperação com empresas multinacionais tem sido mais restrita e o esforço tecnológico, nesse último caso, concentrou-se na adaptação de produtos e técnicas às condições e mercados da região.

Mais recentemente observa-se, em toda a América Latina, uma pronunciada redução da parcela do orçamento público destinada às Universidades, um aumento dos fundos para projetos específicos e um crescimento significativo da participação das IES particulares nas matrículas (SuTZ, 1994). Tomando esse quadro como referência, vários autores defendem que a aliança com o setor produtivo seria uma fonte alternativa de recursos financeiros adicionais.

Alguns estudiosos consideram que "a vinculação Universidade - Setor Produtivo [seria] uma ferramenta para apoiar uma transformação muito profunda da sociedade, que vai além das necessidades conjunturais das Universidades ou de algum problema pontual das empresas" (SuTz, 1994, 58). No entanto, a América Latina ainda registra um número pequeno de trabalhos cooperativos entre UxE.

No Brasil, assim como no restante da América Latina, as experiências de relacionamento UxE são escassas, o que tem sido explicado, entre outros, com os seguintes argumentos: a) tentativa de construção, apenas nos anos 1960, de um sistema nacional de C\&T; b) falta de estabilidade e coerência entre as políticas implícitas e explícitas dos governos ${ }^{9}$; c) modelo de industrialização baseado na importação de tecnologias; e d) falta de tradição das empresas nacionais em buscar desenvolver e até mesmo conhecer novas tecnologias.

Apesar disso, observa-se que tanto Universidades quanto empresas têm se dedicado ao desenvolvimento de mecanismos de interação, seja por 
meio da implantação de escritórios de transferência de tecnologia (que recebem denominações variadas) ou de programas de incentivo à parceria. No entanto, até o momento, os resultados positivos para os esforços empreendidos são pontuais, gerando a necessidade de compreender melhor os elementos envolvidos nestes casos, bem como as peculiaridades da realidade brasileira.

Nota-se que, de maneira geral, a bibliografia produzida sobre este tema tende a centrar-se no 'diagnóstico' dos problemas de interação na região e a fazer recomendações normativas baseadas nas experiências dos países centrais, muitas vezes sem considerar diferenças estruturais significativas entre eles. $\mathrm{O}$ problema reside no fato de que a experiência dos países centrais, dadas suas peculiaridades e especificidades, inviabiliza uma simples transposição de mecanismos e de modalidades de interação para os países periféricos.

Considerando tais diferenças e a fim de caracterizar a dinâmica interna dos casos de cooperação UxE no Brasil, foi feito um estudo utilizando dados bibliográficos e empíricos, cujos resultados apresentamos a seguir.

\section{IV - Dinâmica da cooperação UxEno Brasil:evidências do relacionamento}

A análise de estudos de caso e de entrevistas, aliada às informações mais gerais presentes na literatura nacional e internacional sobre o tema, permitiu a identificação de aspectos recorrentes da cooperação UxE no Brasil. As características mais comuns nos casos estudados foram denominadas "evidências" do relacionamento. Os pontos destacados são representativos, portanto, de fatores que têm contribuído para a conformação/delineamento da relação entre academia e setor produtivo no país.

É importante lembrar que a descrição dessas características não deve ser confundida com a elaboração de um receituário sobre a cooperação virtuosa; trata-se apenas da exposição de um rol de tópicos que se mostraram significativos para uma reflexão sobre a interação UxE no Brasil.

IV.1-Formulação de projeto para o grupo de pesquisa/instituição - pesquisadores, departamentos e/ou instituições parecem ter firmado, para si próprios, objetivos e estratégias para o desenvolvimento da cooperação. Ainda que estes tenham sido parcial ou totalmente reformulados com 0 passar do tempo, adaptando-se às necessidades do contexto, o alcance de resultados positivos - tanto para o meio acadêmico quanto o empresarial - não parece ter derivado do acaso.

É ilustrativo o estudo de Cerantola (1993) sobre o Instituto Butantan de São Paulo que, em plena crise e cenário adverso para as instituições de 
Ciência e Tecnologia no final dos anos 80, conseguiu renovar estrutura, quadros e metas de desenvolvimento em C\&T e de produção em poucos anos. Tendo por objetivo tornar-se um centro nacional de referência na pesquisa e produção de soros e vacinas, o Butantan elaborou um plano estratégico que contemplava: a) investimento na formação de recursos humanos; b) renovação da estrutura organizacional e das instalações físicas e laboratoriais; c) utilização do meio externo como estímulo e parceiro.

Assim como os dados bibliográficos evidenciaram o esforço de instituições universitárias e acadêmicas na elaboração de projetos de aproximação com o setor produtivo, a análise das entrevistas permitiu observar que os grupos de pesquisa que conseguiram estabelecer laços profícuos com o setor empresarial também contaram com estratégias bem definidas de atuação. Um relato bastante esclarecedor a esse respeito, feito por professor de um dos centros de pesquisa da Unicamp, descreveu como uma parceria produtiva pode ser desenvolvida a partir de um plano de pesquisa bem elaborado. $\mathrm{O}$ seu grupo de pesquisa percebeu que uma das áreas em que atuava poderia ser ampliada; tendo isso em vista, inicialmente foi desenvolvida neste centro tese de doutorado que modelava um processo de produção. A partir disso, o grupo procurou empresas potencialmente interessadas no modelo elaborado. Ao conseguir validar e atestar o seu sucesso (mais de 95\% de acerto), o processo desenvolvido foi implantado pelo parceiro, gerando demanda por assistência técnica. O grupo se fortaleceu com essa experiência geradora de oportunidades de outras parcerias no setor. Ou seja, a aproximação com o setor empresarial decorreu de ações planejadas para esse fim. Ainda que tenham sido feitos ajustes no plano inicial, a existência de metas e estratégias de atuação foi fundamental para o estabelecimento da parceria e para 0 seu sucesso.

IV.2 - Excelência acadêmica - esta mostrou-se relevante para a interação com o setor produtivo, embora um alto grau de titulação não seja um imperativo. O princípio das relações entre UxE, bem como sua manutenção, parece passar com freqüência pelo reconhecimento acadêmico do profissional de pesquisa. O mérito acadêmico do pesquisador permite ao empresário/cliente localizá-lo em uma instituição, além de lhe conferir confiabilidade e respeitabilidade. Tal se evidenciou em vários depoimentos dos estudos de caso. "O salto qualitativo de nossas relações com a indústria não decorreu de nenhuma medida específica (...) foi uma decorrência do esforço pessoal dos professores. Nosso único mérito nisso foi ter investido sistematicamente na capacitação pessoal de todos. Com a capacidade que eles têm, acabam cavando trabalhos de nível, que geram conhecimento." (Castro, 1993, 13)

A excelência acadêmica muitas vezes parece mais relevante para explicar a capacidade de interação dos profissionais de pesquisa com o setor 
produtivo do que um perfil teórico ou aplicado das atividades desenvolvidas pelos pesquisadores. O estudo de PERRE (1995) sobre alguns departamentos da USP/São Carlos é ilustrativo a este respeito. Devido à excelência acadêmica, 0 departamento de Física, tradicionalmente mais teórico, desenvolveu relações mais estreitas com o setor produtivo que o de Engenharia Elétrica da mesma instituição, que possui perfil aplicado (p. 285).

As entrevistas revelaram que os parceiros procurados pelas empresas são, freqüentemente, pesquisadores cuja excelência acadêmica pode ser constatada pela publicação de trabalhos em revistas auditadas e pela participação em congressos. Foi possível notar, inclusive, que diversos pesquisadores foram localizados pelas empresas através desses meios.

Um alto número de publicações não facilita apenas o contato com 0 setor produtivo; ele é fator essencial para a permanência de grupos de pesquisa nas Universidades. Tal foi demonstrado por BRISOLA \& GuEDEs PinTo (1995), que descrevem a atuação de dois grupos do Instituto de Física da Unicamp com estreitos laços com o setor produtivo. Enquanto um deles apresentava alto rendimento acadêmico (em número de teses, publicações), o outro, apesar de possuir forte contato com empresas, foi pressionado a sair da Universidade por haver descuidado da publicação de trabalhos científicos.

Existe a percepção, entre os entrevistados, de que uma maior titulação do quadro docente pode auxiliar na estratégia de captação de recursos. Mas muitos deles também parecem considerar que apenas a titulação/produção acadêmica não é o bastante para que seja firmada a cooperação. “...hoje em dia 0 ciclo tecnológico na minha área é de seis meses. Eu posso ser titular e daqui a seis meses estar fora da realidade. E alguém que atua na produção e não tem título nenhum saber mais do que eu (...) O título é coisa que se consegue por esforço acadêmico, mas a realidade é outra...". (docente da Unicamp)

IV.3 - Coesão do grupo - o retorno dos investimentos na consolidação de uma estrutura e de um grupo de pesquisa torna-se maior à medida que este mantém-se coeso e, do mesmo modo, a coesão de um grupo de pesquisa aumenta à medida que os investimentos na qualificação de recursos humanos são revertidos para o próprio grupo, permitindo o aprofundamento das pesquisas realizadas. Tal se evidencia em SBRAgia \&TerRa (1993, 22): "Talvez o fato mais notável do desenvolvimento tecnológico da empresa, seja o fato da EMBRAER ter mantido, ao longo de seus 20 anos de existência, praticamente toda a sua equipe técnica, permitindo assim um contínuo aperfeiçoamento da mesma. Os vários projetos da empresa são, de alguma forma, uma continuação do anterior...".

Várias entrevistas também revelaram que a coesão/solidez do trabalho desenvolvido pelo grupo são determinantes para o estabelecimento da 
cooperação: "Nós já tínhamos um trabalho de muitos anos, já éramos conhecidos. Por isso nós fomos procurados. Era um trabalho muito grande também, que acho que outros laboratórios não tinham, talvez, capacidade operacional de realizar no prazo solicitado. Nós tínhamos equipamento, bom laboratório e pessoal de boa qualidade (...) Só com o passar do tempo outros grupos foram se especializando nessa área." (professor da Unicamp).

Muitas entrevistas asseveraram que o relacionamento UxE pode trazer benefícios para a consolidação do grupo. Em uma parceria estabelecida na Unicamp, os recursos advindos do contrato possibilitaram visitas e contatos com pesquisadores de laboratórios de outros países, facilitando a internalização de novas técnicas. Além disso, permitiu que pesquisadores de outras Universidades e centros de pesquisa brasileiros pudessem colaborar num curso de pós-graduação. Ou seja, o grupo foi fortalecido na sua qualificação e nas oportunidades de atualização em decorrência da disponibilidade de recursos obtidos nas parcerias com a empresa.

IV.4 - Intermediação de alunos na cooperação - dentre as diversas formas de interação UxE (tais como contratos de pesquisa, convênios, prestação de serviços, cursos de extensão), nos dados analisados destacaramse as relações desencadeadas por intermédio de alunos de graduação e/ou pós-graduação. Embora os vínculos possam ser, em um primeiro momento, entre alunos e empresas, estes abrem caminho para uma interação mais ampla. A atuação de alunos em estágios, empresas-júnior e no mercado de trabalho, por exemplo, propicia às instituições acadêmicas contatos para pesquisa, além de auxiliar na atualização da Universidade com relação às demandas do setor produtivo.

O estudo de Quirino (1993) aponta a formação de uma "rede" de influências, na interação entre Universidade e setor produtivo, a partir dos alunos:

...os estudantes que de alguma forma se integraram ao grupo durante seus cursos na UFV, ou foram expostos ao desenvolvimento das pesquisas, são (...) ponte de ligação com o setor produtivo. Seu posicionamento privilegiado no mercado de trabalho e na estrutura social, como gerentes de fazendas, de empresas agropecuárias e cooperativas, produtores rurais ou pesquisadores, deputados ou administradores públicos, tem sido de vital importância para que novos convênios sejam negociados. Além disso, muitos dos melhores grupos de pesquisa de soja no país contam com a cooperação de cientistas formados sob a influência do programa, o que os torna difusores constantes dos avanços ali conseguidos. (p.17).

A importância da intermediação de estudantes para o contato e estabelecimento de cooperação com o setor empresarial foi corroborada nas entrevistas. Relato de professor da Politécnica, por exemplo, atesta que a atua- 
ção, na indústria, de dois bolsistas do seu grupo, permitiu o estabelecimento de uma parceria para o desenvolvimento de um novo produto. Segundo o professor, sem o intermédio dos alunos, ele não teria identificado a demanda e a cooperação não teria ocorrido.

Os pesquisadores consideram, portanto, que os estudantes são uma "ponte"/elo com as empresas, conforme se observa na seguinte declaração de um pesquisador do IPT. "Um pesquisador que esteve aqui outro dia contou que quando ele divulga sua pesquisa num congresso, de cada 1000 pessoas, 2 se interessam pelo assunto. Se ele faz uma mala-direta, de cada 200, um se interessa. Se ele faz visita a empresas, de cada 10 empresas, 2 se interessam. E, no final de um longo processo, um antigo aluno ou então um colega de escola que está em boa posição na empresa, efetivamente inicia a cooperação. Eu também acredito nisso".

IV.5 - Resistência à introdução de uma "lógica empresarial" nas atividades de pesquisa, as diferenças de cultura e de valores entre a academia e o setor produtivo fazem com que alguns setores da Universidade apresentem resistência a comportamentos e tomadas de decisão que contemplem o que denominam "lógica empresarial", embasada no lucro. São vários os exemplos de docentes e instituições que, após desenvolverem projetos de cooperação, enfrentaram resistências no meio acadêmico, como evidencia a fala a seguir: "Eu ouvi, outro dia, um professor declarar, num colóquio, que não faz sentido nenhum a Universidade desenvolver uma técnica para a indústria faturar e lucrar com isso" (CASTRO \& BALÁN, 1994, 33). A causa desta resistência foi explicitada em vários depoimentos:

... os projetos de pesquisa mais aplicada, realizados com empresas, são vistos com um pouco de restrição pelos colegas que só fazem pesquisa básica. Eles tendem a achar que a gente é um mercador, que está se vendendo. Nos colegiados eles mostram um certo desdém pelas nossas atividades. Muitas vezes estabelecem uma valoração secundária para o trabalho que fazemos. A complementação salarial que esse tipo de projeto permite também é severamente criticada (docente da Unicamp).

Alguns docentes também registraram que existe, por parte de setores da Universidade e dos institutos públicos de pesquisa, preocupação com a preservação da imagem que estes possuem perante a sociedade. "Veja bem, um instituto de pesquisa deve tomar algumas precauções nas relações com empresas. Recentemente o IPT realizou um laudo para uma empresa e esta utilizou (de comum acordo, diga-se de passagem, pois estava previsto no contrato) o nome do IPT em um material de divulgação. Será que os recursos obtidos com essa 'prestação de serviços' compensam a perda de credibilidade da instituição junto a outras esferas? Eu acho que não" (pesquisador do IPT). 
Mas por parte da empresa também observa-se, freqüentemente, dificuldades de compreensão em relação ao trabalho desenvolvido na Universidade, o que traz dificuldades para o desenvolvimento de projetos em conjunto. SteFAnUTTO (1995) abordou esta questão: a hostilidade de alguns funcionários de uma empresa para com um grupo de pesquisadores da Universidade, contatados para o desenvolvimento de um projeto, gerou situações de conflito e atrito direto, prejudicando o alcance de resultados.

\section{IV.6 - Definição prévia e clara dos objetivos da interação - foi} constatado que boa parte dos "choques culturais" deve-se ao fato dos objetivos não terem sido claramente definidos e/ou do contrato ser omisso em detalhes importantes. Assim, no caso relatado por STEFanUtTo (1995), as diferentes expectativas da empresa e da Universidade em relação ao software, objeto do contrato, entre outros, conduziram a conflitos: a empresa queria que "o projeto fosse entregue na forma de "pacote" de software, ou seja, em formato quase comercial, com manuais de instruções elaborados e uma interface de comunicação com os usuários bastante simplificada"; a Universidade, por seu lado, entendia que o produto seria entregue necessitando diversos ajustes (p.154). Questões como estas, não previstas no momento de redação do contrato, geram problemas significativos de relacionamento entre os atores.

Nas entrevistas este aspecto também foi abordado. Em projeto sobre plantas de uso popular que tinha por objetivo comprovar a atividade terapêutica das mesmas, para em seguida gerar potenciais produtos para a indústria farmacêutica nacional, houve grande diferença no entendimento das funções de cada parceiro: enquanto para os pesquisadores da Universidade a meta era identificar e catalogar o maior número de plantas, para a empresa interessava selecionar a mais promissora e aprofundar na pesquisa sobre sua utilização. Essas diferenças no entendimento conduziram à desativação do projeto.

IV.7 - Dificuldade de consolidação de relações - até mesmo unidades, instituições e/ou grupos de pesquisa idealizados com a finalidade de interação com o setor produtivo enfrentam dificuldades para a sua estruturação. MERCADo (1995), em estudo sobre o Centro de Pesquisas Químicas, Biológicas e Agrícolas da Unicamp (CPQBA), destaca tal fato. Foram determinadas as áreas prioritárias de atuação, estudadas as demandas do setor produtivo e estabelecidas estratégias para estimular a interação. No entanto, os objetivos de atração de clientes e a meta de autonomia financeira não foram alcançados: cinco anos após haver sido criado, cerca de $70 \%$ dos recursos do CPQBA ainda eram provenientes da Universidade. Segundo o autor, questões relativas ao mercado (como a retração da indústria química) e ao contexto tornaram inviável o desenvolvimento de parcerias com o setor produtivo no nível que se esperava inicialmente. 
No que se refere ao contexto, cabe destacar que o tipo de demanda requerida pelo setor produtivo é determinante da natureza da relação UxE, como mostra RAcHID (1995) no estudo sobre o Programa de Engenharia de Materiais (DEMA) da USP/São Carlos, criado com a intenção de atender à necessidade das empresas do parque tecnológico instalado na região (de profissionais qualificados e P\&D). Apesar da elevada qualificação docente, da existência de laboratórios de P\&D na área de materiais e processos e da proximidade do setor produtivo, o DEMA ainda tem papel limitado, tendo em vista seu objetivo inicial de interação com as indústrias.

Outra dificuldade da Universidade para estabelecer a chamada 'cooperação virtuosa' com o setor produtivo reside na falta de tempo e encaminhamento adequados aos projetos de interação, de modo a qualificar/ convencer o cliente a desenvolver e investir em C\&T (CASTRO\&BALÁN, 1994b).

Um outro aspecto fundamental para o encaminhamento da cooperação, ressaltado nas entrevistas, diz respeito à boa interlocução entre as partes, pois a vivência (inclusive a linguagem) de ambas é bastante diferenciada. " $O$ grande problema das Universidades é justamente esse, é uma coisa muito acadêmica. As pessoas que estão fazendo isso não têm a menor experiência nessa área, pelo menos com as empresas. Eles são muito bons pesquisadores, ótimos docentes, mas nunca foram empresários, com algumas exceções. Eles não sabem nem a linguagem, e então não há conversa (...)"(docente da Unicamp).

\section{IV.8 - Criação de estruturas que auxiliam na resolução de ques-} tões técnicas e burocráticas - o estabelecimento de um vínculo formal entre o meio acadêmico e o setor produtivo traz aos pesquisadores preocupações quanto ao formato dos contratos, administração dos recursos obtidos, registro de patentes, compra de equipamentos, contratação de pesquisadores e/ou técnicos, dentre outras. O estudo de PERRE (1995), por exemplo, dá várias indicações de que a constituição de redes/relações externas necessita do apoio e legitimação oferecidas pela instituição acadêmica. Na mesma linha, LovERA (1995) relata como a criação do Instituto de Desenvolvimento Experimental/ IDEC, na Faculdade de Arquitetura da Universidade da Venezuela possibilitou não só o crescimento da pesquisa aplicada, como também estimulou a criação de uma empresa para facilitar a relação e captação de recursos do setor produtivo.

A criação de estruturas de apoio à cooperação UxE foi, portanto, bastante destacada como uma saída para o enfrentamento de obstáculos burocráticos decorrentes da estrutura administrativa estatal. Dentre os mecanismos existentes, o de Fundações foi um dos mais citados nos estudos e entrevistas. O estudo de CASTRO \& BALÁn (1993c) é um dos que revela como a criação de uma fundação - a Fundação Instituto de Pesquisas Econômicas/FIPE - permi- 
tiu a pesquisadores do Instituto de Pesquisas Econômicas (USP) flexibilizar a estrutura burocrática universitária que não estava preparada para captar e gerenciar as receitas auferidas. A FIPE ampliou o campo de atividades de pesquisa, complementou salários e, além disso, teve papel decisivo na formação da competência acadêmica do grupo pela concessão de bolsas de pósdoutoramento (p.16). Depoimentos de vários docentes também ressaltaram a necessidade de mecanismos para intermediar a resolução de questões burocráticas.

Os contratos, normalmente, são feitos através da Funcamp. Para mim isso é tranqüilidade administrativa. Sem o apoio da Funcamp, eu realmente não me animaria a estar estabelecen do um novo convênio agora, por exemplo. Eu não tenho disponibilidade de tempo e mesmo de usar a minha capacidade para estar administrando ... envolve pessoal, tem muita coisa complica da (...). Ela executa as compras, o pagamento de pessoal. Eu acho isso a maior vantagem. Essas coisas eu não sei fazer. E não quero utilizar o meu tempo, o meu esforço para isso (docente da Unicamp).

É por isso que a criação de órgãos e mecanismos de apoio à interação com empresas, até mesmo dentro dos próprios grupos de pesquisa e departamentos, apresenta-se hoje como um mecanismo que, somado a outros fatores, parece contribuir em muito no suporte à cooperação.

"Nós temos aqui um setor que faz pesquisa de preço, contato com fornecedores. Ele dá todo o suporte: faz tomada de preços, elaboração de uma primeira proposta de custos, e passa para a Funcamp já nos formulários que ela pede. A pessoa que faz isso já está aqui há dez anos; quando ela recebe 0 pedido já sabe 0 vidro que tem que comprar, o reagente, 0 gás. Isso nem o pesquisador, às vezes, sabe direito onde encontrar" (pesquisador da Unicamp).

A bibliografia analisada descreveu uma diversidade de estruturas, organizações e formas de atuação das Fundações. Em alguns casos elas foram criadas há anos, e passam (ou já passaram) por reformulações, visando a aperfeiçoar sua sistemática de atuação (como no caso da FIPE). Em outros, elas parecem não ter atingido até o momento o grau de eficiência/retorno institucional desejado (CASTRO, 1993, 29). Há, também, aquelas cuja atuação parece bastante satisfatória (caso sobre o INCOR (PEREIRA, 1993). Algumas unidades/departamentos criaram sua própria estrutura de organização e gerenciamento da relação com o setor produtivo que, atuando em conjunto com a estrutura da Universidade, oferece o respaldo necessário ao pesquisador. 
IV.9 - Presença de um 'professor-empreendedor' - tanto os estudos de caso quanto as entrevistas destacaram o papel exercido por líderes de pesquisa/institucionais com trânsito acadêmico-político, capazes de captar recursos e fechar contratos com empresas. No atual contexto de cortes e enxugamento estatal dos recursos destinados à C\&T, a instituição acadêmica parece requerer profissionais que vão além da competência técnica localizada, ou seja, que conciliem competência acadêmica com desenvolvimento de temas de pesquisa que, de alguma forma, possam catalisar recursos a serem revertidos em prol do grupo/instituição. É possível, no entanto, que ao longo de um projeto a liderança mude de mãos, pois nem sempre o líder que dá início à colaboração é o requerido numa fase posterior da cooperação ${ }^{10}$.

O estudo de CASTRO (1993) sobre o Departamento de Engenharia Mecânica da UFSC é bastante ilustrativo a este respeito. Tendo sido constituído como um centro de pesquisa e de formação de professores e pesquisadores, ele consolidou-se com uma política de qualificação de professores em áreas diversificadas e comprometidos com o limite do conhecimento produzido no exterior. A crescente deterioração do sistema federal de apoio à C\&T, porém, fez sentir a necessidade de usar a pesquisa contratada para gerar pesquisa de ponta. Contatos estabelecidos anteriormente com o setor produtivo (para oferecimento de estagiários e serviços) foram retomados e, a partir disso, coube aos próprios professores "cavar trabalhos de nível" a partir dos problemas enfrentados e oferecidos pelas empresas, vinculando o atendimento à indústria com a produção científica (CASTRO, 1993).

A primeira questão para qualquer empresário é saber qual será o retorno do investimento e em que prazo. Temos que fazer este cálculo, falar esta língua. Depois, temos que enfrentar a imagem que a Universidade tem de furar prazos e a questão do risco que a pesquisa tecnológica envolve. Estamos entrando no problema da especificação do contrato e isto é um processo que não se resolve no primeiro contato (...). Cada indústria é uma indústria, precisamos identificar o problema e trazer a discussão para o plano concreto, inclusive porque, muitas vezes, o diretor que está nos contratando não sabe direito o que quer... (p.24-25).

A busca por recursos parece estar levando alguns professores a uma nova atitude voltada para o alavancamento de projetos em cooperação com 0 setor produtivo. "Eu não fico aqui aguardando, esperando o empresário vir falar comigo, eu vou até o empresário, essa é a grande diferença. O nosso trabalho é muito agressivo (no bom sentido) com relação às empresas. Nós nos aproximamos delas usando todos esses canais e todas essas vias, seja palestras, ou pela imprensa; enfim, seja o canal que for nós vamos atrás das empresas" (docente da Politécnica). 
Há nesta atitude a tendência de fazer com que o professor universitário venha a incorporar, crescentemente, novas características, conforme fica evidente no depoimento seguinte:

Eu combino tudo antes com o empresário: royalties, valores, tudo como se faz normalmente no mercado. Nós temos algumas minutas de convênio padrão,... e nessa minuta padrão constam as regras básicas da Universidade que a gente não fura. Isso o empresário vai ter que aceitar previamente, as taxas, aquela coisa toda. (...) Nós discutimos tudo antes e depois que está tudo combinado fazemos um contrato em cima daquilo que foi discutido, daquilo que foi acertado complementando as regras gerais. É assim que se faz no mercado, é exatamente assim. Se vocêvai comprar uma casa, discute antes o preço, como vai pagar, e depois faz o contrato em cima daquilo, prá que o combinado seja cumprido (docente da Unicamp).

Dentre os vários pontos destacados até aqui (itens 1 a 9), alguns referiram-se a dificuldades para a cooperação UxE e, outros, a pontos que facilitam sua intermediação. Mas houve dois que denotaram atitudes novas no sentido de conferir maior suporte/apoio à interação. Trata-se dos dois últimos itens, que revelam mudanças de postura dos atores acadêmicos, tornando-os mais proativos na busca de recursos para pesquisa. Diante disso, tem-se um ponto de convergência entre as características da relação UxE no Brasil e as transformações apontadas pela literatura internacional.

\section{V - Considerações sobrea relação Ux Eno Brasileimplicações para a Avaliação Institucional}

Este trabalho não teve por objetivo fazer um diagnóstico dos países centrais e aplicá-lo aos periféricos. Conforme afirmado anteriormente, quaisquer observações que estabeleçam comparações e correlações entre eles devem ser analisadas com cuidado. O que se pretende destacar, neste momento, é que o resultado da análise de dados do caso brasileiro indica um movimento de mudanças - quanto ao perfil do pesquisador e à estrutura organizacional da pesquisa - que se processa na mesma direção dos países centrais. Em outras palavras: países centrais e periféricos têm assinalado a ocorrência de alterações semelhantes, nas IES, a partir das relações UxE.

Tal fato é indicativo, para alguns autores, de um fenômeno global referente a transformações quanto ao modo de produção do conhecimento, ou seja, à forma como pesquisadores e instituições tendem a se relacionar com o fazer científico. O estudo de VelHo (1996) sobre como as atividades acadêmicas de ensino e pesquisa de três Universidades brasileiras têm sido alteradas em sua natureza (objetivos e forma de organização) em decorrência 
de consórcios entre UxE faz algumas considerações a este respeito. Segundo a autora, as relações UxE têm provocado transformações nas atividades de ensino e pesquisa que estariam colocando em jogo não só a lógica da atividade acadêmica, mas também os seus padrões de produção. Embora os dados existentes ainda não permitam concluir se ocorrem modificações no ethos organizacional, constatou-se que esta é uma tendência crescente (p.134;139).

O Brasil parece seguir, portanto, uma tendência mundial em que 0 questionamento do modelo mertoniano (do fazer pesquisa desinteressada) estaria vinculado a transformações no acesso aos resultados da pesquisa, mas também no próprio modus operandi de pesquisadores e instituições. Tomando esta hipótese como verdadeira, é possível fazer projeções de alterações em dois aspectos referentes ao comportamento dos atores envolvidos na interação UxE. São eles:

1 - Flexibilização da estrutura organizacional da pesquisa, uma vez que organismos de flexibilização da burocracia da Universidade parecem fundamentais para o estabelecimento de cooperação com o setor produtivo, tendo em vista as dificuldades encontradas pelos professores/pesquisadores ao lidar com questões de natureza administrativa. A grande quantidade de referências a fundações e estruturas de apoio (montadas pelas instituições, departamentos ou grupos de pesquisa), nos dados analisados, é indicativo do quanto estas podem contribuir para a melhoria da interação e de que mecanismos de apoio à realização de contratos e administração da pesquisa podem ser decisivos para o bom andamento da cooperação.

A flexibilização da estrutura não implica, apenas, na realização de serviços de administração/gestão da pesquisa, mas também em ações facilitadoras da aproximação entre UxE, o que ainda é bastante requisitado pelos docentes.

Isto não significa, no entanto, que a simples criação de órgãos e mecanismos institucionais de aproximação, ou que um auxílio legal-administrativo para a formalização de contratos possam garantir resultados positivos de interação. STAL (1994), em estudo sobre mecanismos que formalizam o relacionamento entre Universidade e setor produtivo, destacou várias Universidades norte-americanas que não possuem Fundações ou regras predeterminadas para este fim e, apesar disso, tais relações têm importância no âmbito da instituição.

2 - Mudança no perfil do pesquisador, pois a necessidade de recursos para a subsistência do grupo de pesquisa/departamento, juntamente com as novas formas de organização/produção da pesquisa (formação de redes e desenvolvimento de projetos interdisciplinares e em grupo), têm provocado mudanças no perfil "tradicional” do professor universitário. Este pas- 
saria a necessitar saber conciliar, à sua competência acadêmica, a capacidade de elaborar projetos atrativos de clientes/parceiros, além de saber negociar contratos. Este novo perfil reuniria, portanto, habilidades como: identificar temas de pesquisa de interesse para o setor produtivo; elaborar estratégias de cooptação de clientes; consolidar relações com seus parceiros; tirar proveito de espaços e estruturas institucionais que auxiliem na interação com as empresas.

A criação, dentro dos próprios grupos de pesquisa e departamentos, de órgãos e mecanismos de apoio à interação com empresas pode ser considerada indicativo deste novo perfil de pesquisador que estaria buscando, por iniciativa própria, criar/refinar mecanismos de suporte à cooperação.

\section{VI - Conchusões}

Os resultados deste trabalho indicam um movimento de mudança em várias instituições de ensino e pesquisa brasileiras quanto à forma de produção do conhecimento e do saber científico. É possível imaginar que tal vem refletir em vários aspectos do funcionamento e desenvolvimento de suas atividades, como: sistema de gestão; estrutura organizacional; estabelecimento de critérios de contratação; avaliação do ensino de graduação e da produtividade docente, entre outros.

As implicações destas transformações para um processo de Avaliação Institucional que seja comprometido com a melhoria da qualidade da instituição mas, principalmente, com o estabelecimento de princípios que permitam formular as bases de um projeto institucional calcado na realidade e nas necessidades do contexto em que está inserido também parecem ser significativas.

Num primeiro momento, desponta que o relacionamento das IES (que desenvolvem atividades de ensino e pesquisa) com o Setor Produtivo deve merecer atenção e estudo por parte de pesquisadores e de administradores universitários, uma vez que tendem a provocar alterações na estrutura acadêmica. GoERGEN (1997) mostra por que a Universidade vê-se, atualmente, diante de questões que afetam sua "dimensão fundante" e indica como uma avaliação que não se restringe à mensuração de performance das funções tradicionais (de ensino, pesquisa e extensão) pode contribuir para a construção de uma nova identidade para a instituição (p.64).

No nível prático, a importância de analisar a ocorrência de alterações fica clara se considerarmos, por exemplo, que a obtenção de recursos para pesquisa junto às agências financiadoras pode depender do quanto as instituições estariam aptas a processar internamente as mudanças apontadas.

Um outro ponto que implica diretamente na Avaliação Institucional 
diz respeito à elaboração de novos indicadores que contemplem a contribuição das Universidades para o desenvolvimento econômico regional. Se, por um lado, tal faz-se fundamental para viabilizar a mensuração das atividades desenvolvidas com este fim, não menos importante é que este processo se dê em constante reflexão e controle para que a instituição universitária não fique restrita à perspectiva de colocar-se a serviço dos interesses do mercado (VELHO, 1996, 146) .

Finalizando, cabe destacar que mesmo as IES que desenvolvem preponderantemente atividades ligadas ao ensino de graduação devem levar em conta as novas demandas e desafios trazidos pelo setor produtivo para as Universidades. Pois as mudanças que podem advir de um novo modelo de organização das funções e atividades universitárias provavelmente irão, num curto prazo, influenciá-las.

\section{Notas}

1 Artigo baseado em estudos e em entrevistas realizadas no escopo dos projetos de pesquisa: "Universidade \& Empresa: Ciência \& Tecnologia" e "Estudo dos Centros Pioneiros na Integração com o Setor Produtivo", ambos coordenados pela Profa. Drạ. Sandra N. Bisolla (IG/Unicamp). As pesquisas contaram com financiamnto da FINEP e do CNPq, aos quais agradece-se ao apoio concedido.

2 Ver Brisolla, S.N. (Coord.) Universidade \& Empresa; Ciência \& Tecnologia - Relatório Final. Campinas, DPCT/Instituto de Geociências, abril de 1998.

3 A relação dos estudos de casos analisados pode ser encontrada nas Referências Bibliográficas.

4 As entrevistas foram realizadas como parte da pesquisa empírica dos projetos de pesquisa citados anteriormente. Em nenhuma transcrição os nomes dos entrevistados serão mencionados, tendo em vista 0 compromisso firmado entre pesquisadores e entrevistados a este respeito.

5 Maiores detalhes sobre propostas de Universidade com este perfil podem ser encontradas em: Webster E Etzkowitz (1991); Etzkowitz E Peters (1991); Webster (1994 A E B); Etzkowitz (1994) E Leydersdorff E Etzkowitz (1997).

6 Um dos exemplos mais citados desse tipo de acordo foi o firmado entre a Hoechst e o Massachusetts General Hospital, no valor de US\$ 50 milhões (Dickson, 1988).

7 Nesse caso o exemplo mais citado é a participação da Harvard University em uma empresa de Biotecnologia criada por um de seus ex-professores. Após uma primeira manifestação positiva sobre a participação da universidade, o 'reitor' teve que desistir pois não havia normas que regulamentassem o comportamento desta instituição em casos de lucros, mas principalmente em caso de prejuízo. Mais tarde a Harvard, através dos escritórios, regulamentou sua participação em empresas criadas por professores a ela vinculados (EтzкоwiтZ, 1989).

8 Para R. Merton a Ciência, enquanto instituição social, é organizada segundo normas e valores específicos e seu mecanismo de sustentação compreende um conjunto de imperativos institucionais: universalismo, comunalismo, desinteresse e ceticismo organizado (detalhes sobre este modelo são encontrados em Merton, 1970/1942 e Merton, 1970).

9 Política explícita refere-se aos documentos, planos e programas divulgados; política implícita refere-se ao 
conjunto de ações efetivamente executadas. Para HERRERA (1973), a desconexão entre ambas explicaria grande parte dos fracassos das políticas públicas.

10 Observação feita pelo Prof. Tirso Sáenz, professor visitante que colaborou no Projeto de Pesquisa que deu origem a esse artigo.

\section{Referências Bibliográficas}

\section{BRISOLIA, S. N. (Coord.). Universidade \& Empresa; Ciência \&Tecnologia}

- Relatório Final. Campinas, DPCT/Instituto de Geociências, abril de 1998.

BRISOLA, S. N. e GUEDES PINTO, L.A.C. El Instituto de Física de la UNICAMP y el desarrollo de la telefonía en el Brasil: un caso de articulación eficaz de intereses. In: VESSURI, H. (org.) La academia va al mercado: relaciones de científicos académicos con clientes externos, Caracas: Fondo Editorial FINTEC,1995. pp. 41-63.

CARVALHO, S. T. Acuerdos industriales y actores sociales: la interación entre la Industria y la Facultad de Ingenieria de Alimentos de la Unicamp. In: VESSURI, H. (Org.). La academia va al mercado: relaciones de científicos académicos con clientes extemos Caracas: Fondo Editorial FINTEC, 1995. pp.241-259.

CASTRO, M. H. Estudo dos Centros de Excelência: Departamento de Engenharia Mecânica da Universidade Federal de Santa Catarina. In: Cadernos de Gestão Tecnológica n. ${ }^{\circ}$ 4. São Paulo: NPGCT/USP, 1993. 49pp.

CASTRO, M. H. M. \& BALÁN, J. Universidade versus setor produtivo: a perspectiva e a realidade da Universidade - Caso 1: Os Institutos de Física Glebb Wataghin da UNICAMP (IFGW) e o da USP (IF). São Paulo: NUPES, julho/1994a. 41pp. (Série Documentos de Trabalho, n. ${ }^{\circ}$ 7/94)

Universidade versus setor produtivo: perspectiva e realidade da Universidade - Caso 2: A Faculdade de Engenharia Elétrica da UNICAMP e os três Departamentos da Engenharia Elétrica da Escola Politécnica da USP. São Paulo: NUPES, agosto/1994b. 52pp. (Série Documentos de Trabalho, n. ${ }^{\circ}$ 8/94)

Universidade versus setor produtivo: perspectiva e realidade da Universidade - Caso 3: O Instituto de Economia da UNICAMP (IE) e o Departamento de Economia da FEA-USP. São Paulo: NUPES, agosto/1994c. 38pp. (Série Documentos de Trabalho, n. ${ }^{\circ}$ 9/94).

CERANTOLA, W.A. O caso do Instituto Butantan. In: Cadernos de Gestão Tecnológica n. ${ }^{\circ}$ 2. São Paulo: NPGCT/USP, 1993. 46pp. 
COWEN, R. The Evaluation of Higher Education Systems. WYE, 1996. London: Koogan Page, 1996.

DIAS SOBRINHO, J. Universidade Pública e processos de Privatização da Educação Superior: papéis da Avaliação Institucional. In: Revista Avaliação, RAIES, Campinas, SP, v.2, n.4, pp. 57-64, dez.1997.

DICKSON, D. The new politics of science. Chicago: Univ. of Chicago, 1988. 403pp.

DIERDONCK e outros University-industry relationship: how does Belgian academic community feel about it? In: Research Policy, 1990.

ETZKOWITZ, H. Entrepeneurial science in the academy: a case of transformation of norms. In: Social Problems, V. 36, N. 1, p. 14-29, Feb. 1989.

Academic-industry relations: a sociological paradigm for economic development. In: LEYDERSDORFF L e VAN DEN BESSLAAR, P. Evolutionary economics and chaos theory: new directions in technology studies. London: Pinter Publishers, 1994. pp. 139-151.

ETZKOWITZ, H.; PETERS, LS. Profiting from knowledge: organizational innovations and the normative changes in American universities. Minerva, v. 29, n. 2, pp. 133-166, 1991.

GOERGEN, P. A Avaliação Universitária na perspectiva da Pós-Modernidade. In: Revista Avaliação, RAIES, Campinas, SP, v.2, n.3, pp.53-65, set.1997.

HERRERA, A. Social Determinants of Science Policy in Latin America (Explicit Science Policy and Implicit Policy). In: COOPER, C. (Org.). Science, Tecnology and Development pp. 21-37. London: Frank Cass, 1973.

LEYDERSDORFF, L \& ETZKOWITZ, H. The future location of research: a triple helix of university-industry-government relations, II, 1997 (Theme paper, Conference New York city, 7-10 january 1998).

LOVERA de Sola, A. Nadando contra la corriente: I\&D en la universidad. In: VESSURI, Hebe. (Org.). La academia va al mercado: relaciones de científicos con clientes externos. Caracas: Fondo Editorial Fintec, 1995. p. 321-346.

MEC - Ministério da Educação, Cultura e Desporto. Dados estatísticos da SEEC. Brasília, 1994.

MERCADO, A. La constitución del Centro de Investigaciones Químicas, Biológicas y Agrícolas de la Unicamp - el CPQBA. In: VESSURI, Hebe (Org.). La academia va al mercado: relaciones de científicos con clientes externos. Caracas: Fondo Editorial Fintec, 1995. pp. 320-345. 
MERTON, R. K. Os imperativos institucionais da ciência. In: DEUS, J.D. (Org.). A crítica da ciência: sociologia e ideologia da ciência. Rio de Janeiro: Zahar Editores, 1970/1942. pp. $37-52$ (originalmente publicado em 1942).

Sociologia: teoria e estrutura. São Paulo: Mestre Jou, 1970. 758pp. (tradução de Social theory and social structure)

PEREIRA, H. M. S. Estudo de Caso: INCOR - Instituto do Coração do Hospital das Clínicas da Universidade de São Paulo. Cadernos de Gestão Tecnológica, nœ 5. São Paulo: CYTED: NPGCT/USP dezembro/1993, 31pp.

PERRE, G. Las relaciones de un grupo de físicos y de engenieros de São Carlos con el setor productivo. In: VESSURI, Hebe (Org.). La academia va al mercado: relaciones de científicos con clientes ex ternos. Caracas: Fondo Editorial Fintec, 1995. pp. 263-291.

PLONSKI, G.A. Novas alianças e parcerias em ciência, tecnologia e engenharia: a cooperação universidade-indústria. In: Anais do XV Simpósio Nacional de Pesquisa em Administração em Ciência e Tecnologia. São Paulo, 1990. pp. G-06.

QUIRINO, T. R. O programa de soja na Universidade Federal de Viçosa. Cadernos de Gestão Tecnológica n. ${ }^{\circ}$ 7. São Paulo: CYTED: NPGCT/USP, dezembro/1993. 33pp.

RACHID, A. El Departamento de Ingenienía de Materiales (DEMA) de la UFSCar. In: VESSURI, Hebe (org.) La academia va al mercado: relaciones de científicos con clientes externos. Caracas: Fondo Editorial Fintec, 1995. pp.209239.

SBRAGIA, R. \& TERRA, J.C.C. EMBRAER: Trajetória de uma empresa de alta tecnologia brasileira. Cadernos de Gestão Tecnológica n. ${ }^{\circ}$ 8. São Paulo: CYTED: NPGCT/USP, dez.1993, 31pp.

STAL, E. Metal Leve S. A. Indústria e Comércio. Cadernos de Gestão Tecnológica n. ${ }^{\circ}$ 1. São Paulo, 1993, NPGCT/USP. 25pp.

La contratación empresarial de la investigación universitaria. Cadernos de Gestão Tecnológica n. ${ }^{\circ}$ 23. São Paulo, 1994 NPGCT/USP. 25pp.

STEFANUTO, G. N. Los límites del éxito de la investigación académica en el ambiente industrial. In: VESSURI, Hebe (org.) La academia va al mercado: relaciones de científicos con clientes externos. Caracas: Fondo Editorial Fintec, 1995. pp. 137-162.

SUTZ, J. Universidad y sectores productivos. Buenos Aires: Centro Editor da America Latina, 1994. 97pp. 
TAKAYANAGUI, A. D. La Universidad Innovadora - una estrategia para el cambio de las Universidades mexicanas en los 90's. Cadernos de Gestão Tecnológica $n .^{\circ}$ 24. São Paulo, 1995. NPGCT/USP. 30pp.

VELHO, S. Relações universidade-empresa: desvelando mitos. Campinas, SP: Autores Associados, 1996. 154pp.

VESSURI, H.M.C. La ciencia académica em America Latina en el siglo XX. Revista de Estudios Sociales de la Ciencia (REDES), v.1, n. ${ }^{\circ} \quad$ 2, Buenos Aires, diciembre 1994. pp. 41-76.

La academia va ao mercado: relaciones de científicos con clientes externos. Caracas: Fondo Editorial Fintec, 1995. 378pp.

WEBSTER, A. J. International evaluation of academic-industry relations: context and analysis. Science and Public Policy, v. 21, n. ${ }^{\circ}$ 2, april $1994 \mathrm{a}$ pp.72-78.

Bridging institutions: the role of contract research organization in technology transfer. Science and Public Policy, v. 21, n. ${ }^{\circ}$, april 1994b . p. 89-97.

WEBSTER, A.J. \& ETZKOWITZ, H. Academic-industry relations: the second academic revolution?London: Science Policy Support Group, 1991. 31pp. (SPSG concept paper, n. ${ }^{\circ} 12$, não publicado)

ZIMAN, J. Research as a career. London: Science Policy Support Group, 1989. 11pp. (SPSG concept paper, não publicado). 